\title{
Adaption of a technique for the accelerated ageing of weed seeds to evaluate their longevity
}

\author{
C.A. Dowsett, T.K. James and P.D. Trivedi \\ AgResearch, Ruakura Research Centre, Private Bag 3123, Hamilton 3240, New Zealand \\ Corresponding author: claire.dowsett@agresearch.co.nz
}

\begin{abstract}
Successful management of weed infestations requires an understanding of their biology including seedbank longevity. The controlled ageing test used by the Millennium Seed Bank, Kew Gardens, was evaluated for several grass and broadleaf weed seeds. The method aims to estimate seed longevity from a seed survival curve, using a controlled environment to accelerate seed ageing. Eight species were tested: nodding thistle (Carduus nutans), white bryony (Bryonia cretica), bat-wing passion flower (Passiflora apetala), butterprint (Abutilon theophrasti), thorn apple (Datura stramonium), apple of Peru (Nicandra physalodes), broomcorn millet (Panicum miliaceum) and yellow bristle grass (Setaria pumila). The suggested measure of longevity is the point where germination has fallen by $50 \%\left(\mathrm{P}_{50}\right)$. Seed survival tested here did not follow the ideal logistic model for analysis. Because of rapid decline in germination, the point where seeds no longer germinate $\left(\mathrm{P}_{0}\right)$ is considered to be a better measure of seed longevity.
\end{abstract}

Keywords controlled ageing test, accelerated ageing, seed testing, seed longevity.

\section{INTRODUCTION}

Seed persistence is defined as the longevity of seeds interacting within their environment (Panetta \& Timmins 2004). In weed eradication and control programmes it is critical to know the characteristics of seeds for the implementation of successful control measures and monitoring. Local eradication is not possible as long as seeds remain viable in the soil and predicting their life expectancy is a challenge (Panetta \& Timmins 2004). Many plants have the potential to disperse thousands of seeds, which may germinate immediately or lie dormant where they are subject to burial, predation or decay. Long-term seed viability is influenced by environmental conditions such as soil type (James et al. 1998), burial depth (Forcella 2003), soil water and temperature (Masin et al. 2005). Genetic factors are a key influence for seed persistence and because of this the survival of seeds experiencing moisture and temperature stress in the laboratory is thought to be a good predictor of their potential persistence in the environment (Bekker et al. 2003). Long et al. (2008) assessed the ability of the controlled ageing test (CAT) used in the Millennium Seed Bank Project by the Royal Botanic Gardens, Kew, UK, to predict seed persistence in the field. Using this they were able to predict relative seed persistence by ranking species based on their CAT $\mathrm{P}_{50}$ values, the time in days taken for seed viability to decline by $50 \%$, as originally described by Newton (2009), and by then comparing these to the known field 
persistence data available from the literature. To describe seedbank persistence, Long et al. (2008) developed three categories: a transient seed bank corresponded to species with a $\mathrm{P}_{50}$ value of $<20$ days ( $<1$ year field persistence), a short-lived seed bank corresponded with $\mathrm{P}_{50}$ values of 20 to 50 days (1-3 years field persistence) and extended persistence corresponded with $\mathrm{P}_{50}$ values of $>50$ days ( $>3$ years field persistence).

The present study evaluated the interpretation of the CAT using Long's rough conversion into the three field persistence categories for its use in current weed management programmes in New Zealand. Eight species were tested using this technique: nodding thistle (Carduus nutans), white bryony (Bryonia cretica), bat-wing passion flower (Passiflora apetala), butterprint (Abutilon theophrasti), thorn apple (Datura stramonium), apple of Peru (Nicandra physalodes), broomcorn millet (Panicum miliaceum) and yellow bristle grass (Setaria pumila).

Broomcorn millet, bat-wing passion flower and butterprint are emerging weeds in New Zealand. Broomcorn millet is a problematic weed in crops of sweet corn in the USA and Canada and is undergoing rapid range expansion in Hawke's Bay, Gisborne and Marlborough (James et al. 2011). Butterprint, also common in America, was found in maize crops in the Waikato in March 2011 (James \& Cooper 2012). Bat-wing passion flower was declared an unwanted organism under the Biosecurity Act 1993 on 24 November 2009, and is invading native bush in Northland, Auckland and Waikato regions (MAF Biosecurity 2010). The remaining species have been tested as they are currently involved in research projects for management and control.

Results from this evaluation will assist authorities to mitigate impacts of weeds to New Zealand's economy and biodiversity, through agriculture, horticulture and forestry, which affect New Zealand's social and cultural values.

\section{MATERIALS AND METHODS}

Seed collection and viability

Plants were grown inside glasshouse facilities during February 2008 for seed collection from broomcorn millet, yellow bristle grass, apple of Peru, thorn apple and nodding thistle. Seed was collected from wild plants in the field for white bryony in March 2006, bat-wing passionflower in March 2010 and butterprint in March 2011. Seed was cleaned and stored inside sealed plastic containers in a cool dry cupboard within a seed laboratory.

\section{Controlled ageing test}

Seeds of eight species were assessed using the controlled ageing test (CAT) according to the standard protocol of The Millennium Seed Bank, Royal Botanic Gardens, Kew, UK (Newton et al. 2009), over a 2-year period from 2009. Fifty seeds of each species were placed into individual open glass vials over a $47 \%$ relative humidity $(\mathrm{RH})$ lithium chloride ( $\mathrm{LiCl}$ ) solution (370 g/litre deionised $\mathrm{H}_{2} \mathrm{O}$ ) within a sealed electrical box at $20 \pm 1^{\circ} \mathrm{C}$ to rehydrate for 14 days. Following rehydration, vials were moved to a second electrical box at $60 \% \mathrm{RH}$ ( $\mathrm{LiCl}, 300 \mathrm{~g} /$ litre) and placed into an oven at $45^{\circ} \mathrm{C}$. This process is known as the controlled ageing test (CAT). Between two and four of the seed vials were sampled randomly at $1,2,5,9,20,30,50,75,100$ and 125 days following transfer into the CAT environment.

\section{Germination test}

For germination testing, two replicates of each species were placed into Petri dishes with sterilised soil and moistened with gibberellic acid (0.1\%), as prescribed by Trivedi et al. (2010), and then placed in a dark incubator at $20^{\circ} \mathrm{C}$. In addition a further two replicates of four of the test species were germinated in the glasshouse where they experienced natural and uncontrolled night and day variations in light and temperature. Petri dishes were checked for germination weekly for up to 6 weeks at which point germination had ceased.

\section{Statistical analysis}

A single line was fitted to the entire data set for each species, by using an exponential followed by a straight (flat) line by using the FITNONLINEAR directive of GenStat (13 ${ }^{\text {th }}$ Edition), which also 
estimated the 'knot' (the point at which the two lines join). However, where an exponential would not fit, a second straight line was used, or in the case of batwing passion flower a quadratic function was employed. Where there was clear evidence of no trend, followed by a sudden drop, two flat lines (the means of each of the two timewise groups of data) were fitted to the data. The assessment of fit comes from the non-zero area of the data.

\section{RESULTS}

Seed viability was tested prior to CAT as was recommended by the protocol. These were as follows: broomcorn millet $78 \%$, yellow bristle grass $80 \%$, apple of Peru $86 \%$, thorn apple $70 \%$, nodding thistle $80 \%$, white bryony $64 \%$, batwing passion flower $90 \%$ and butterprint $90 \%$.

None of the eight species showed the "typical" logistic curve postulated by the Millennium Seed Bank (Figure 1). In the present experiments the species with a hard seed coat: thorn apple, apple of Peru and butterprint, showed a very sharp decline in germination at some point in time, falling to zero between sampling dates (Figure 2 ). For the remaining species, the decline was less rapid but generally started after a single day inside the CAT (Figure 3). For this reason it was impossible to carry out a probit analysis and to determine the $\mathrm{P}_{50}$ value as recommended by Newton et al. (2009).

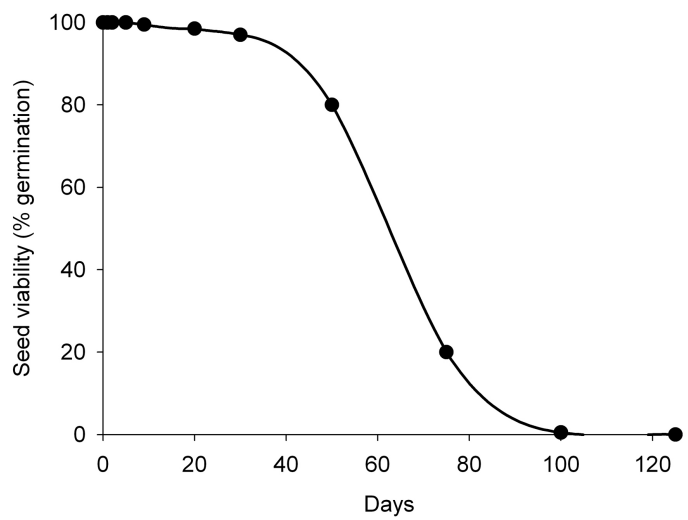

Figure 1 Theoretical seed decay curve as postulated by Newton et al. (2009).

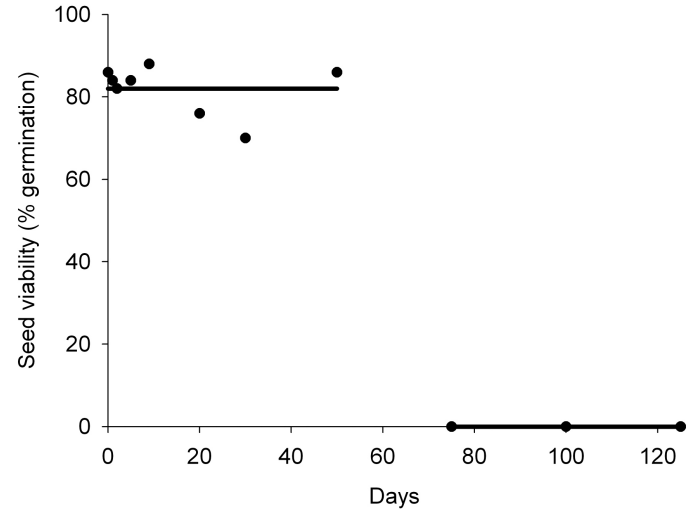

Figure 2 Seed decay curve for apple of Peru.

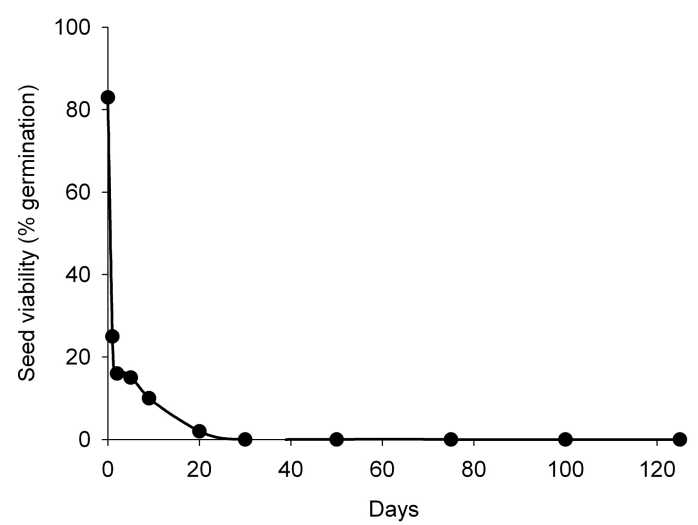

Figure 3 Seed decay curve for yellow bristle grass.

In all these experiments there was no variation in the data once the zero germination point was reached, therefore it is postulated that for these types of seed, a better statistic to assess longevity would be the point (time) at which the seed failed to germinate $\left(\mathrm{P}_{0}\right)$. Where the decline to zero germination occurred over more than a single sampling period (broomcorn millet, bat-wing passion flower, nodding thistle, white bryony and yellow bristle grass), the time when zero germination occurred was determined by carrying out a non-linear regression. For these data, in addition to the time estimate, the standard error (SE) of the point and the fit of the curve (regression value $r$ ) are presented in Table 1. For the remaining species where a curve could not be fitted, only the first zero germination point is presented. 
Table 1 Estimation of time taken (days) to reach zero germination $\left(\mathrm{P}_{0}\right)$.

\begin{tabular}{llcc}
\hline Species & $\begin{array}{c}\mathrm{P}_{0} \\
\text { (days) }\end{array}$ & $\mathrm{SE}$ & $\mathrm{r}$ \\
\hline Nodding thistle & 22.8 & 7.43 & 0.709 \\
Broomcorn millet & 25.3 & 3.86 & 0.944 \\
Thorn apple & 30 & - & - \\
Yellow bristle grass & 30.3 & 15.2 & 0.905 \\
White bryony & 34.6 & 8.2 & 0.677 \\
Bat-wing passion flower & 42.1 & 0.05 & 0.605 \\
Apple of Peru & 75 & - & - \\
Butterprint & 75 & - & - \\
\hline
\end{tabular}

To estimate seed persistence from the CAT results, the point in time when germination becomes zero and stays zero was compared with the categories suggested by Long et al. (2008). Apple of Peru and butterprint were the only species that showed an extended seedbank persistence of $>3$ years. The remaining six species fell into the short-lived seedbank category with persistence of only 1-3 years.

\section{DISCUSSION}

Germination results for the New Zealand weed species tested were initially high, but dropped off rapidly. This may be due to the method of germination used. For example, the four species that were also germinated in the glasshouse produced higher germination than those in the $20^{\circ} \mathrm{C}$ incubator. However, both sets of seed lots stopped germinating about the same time during the CAT and never recovered. This result supports the robustness of the CAT. Despite differing success of germination in varying conditions, individual species seed longevity is the same and indicates that high germination is possibly not required for the CAT to be an effective measure.

Viability testing, such as the tetrazolium stain test, may be a more amenable method of seed testing but results can be misleading (Sawma \& Mohler 2002). While germination testing assesses the ability of a seed lot to produce healthy seedlings, viability tests interpret whether the seed is alive or dead, which may produce a better shaped seed survival curve enabling a clearer prediction of the potential longevity of the seed. However, this would not accurately predict the ability for aged seed to germinate and develop into healthy seedlings.

The literature suggests that these species tested using the CAT may persist for much longer than Long's method of interpretation does. Long et al. (2008) only roughly estimated persistence in the field for 3 years. In a 28 year burial study James et al. (2010) estimated the longevity of nodding thistle to be up to 42 years. Nodding thistle was found to have $30 \%$ germination after 8 years, while thorn apple, also known as jimsonweed, was found to have $23 \%$ germination after 3 years of burial (Burnside et al. 1996). A burial study of green foxtail and yellow foxtail (yellow bristle grass), found that they remained viable and continued to germinate after 6 years of burial (Dawson \& Bruns 1975). In the present study, the conversion of 20-50 days in the CAT, to 1-3 years field persistence appears to be quite inaccurate for the species tested here.

Butterprint has been found to remain almost $100 \%$ viable after 17 years in cropping and tillage systems (Lueschen et al. 1993) and in a separate burial study the seed was found to be up to $17 \%$ viable after 3 years (Uremis \& Uygur 2002). The field persistence category of $>3$ years is therefore too broad. Persistence categories require further work to clearly identify useable time frames of seed longevity to be used for biosecurity. Periods of $0-2,2-5,5-10,10-20$ and $>20$ years would probably be more useful for research and regulatory purposes.

It appears from this study, that more research is required on the interpretation of results from the CAT method to determine the best measure to predict field survival of seed. In this case where $\mathrm{P}_{0}$ was used, the two grasses and nodding thistle had similar values. However, it has been shown that nodding thistle can persist for up to 42 years (James et al. 2010). The soft coated grass seeds would not be expected to persist this long. To better evaluate the persistence of potential seed longevity accurately, "Marker" species should be run on CAT and real time burial studies performed from the same seed lots and at the 
same time. Various methods of germination and viability testing should be investigated to break seed dormancy and give certainty to the results. Sampling of seed from the CAT should be done daily, at least initially, so that sudden collapse in viability can be captured.

When it is improved, the controlled ageing test will have a valuable role to play in understanding the biology of weed species.

\section{ACKNOWLEDGEMENTS}

Many thanks to John Waller, AgResearch, for statistical expertise; Jenni Barr, AgResearch, for assistance with the literature search; and Yasmin Lovell, BScTech student from Waikato University, for technical assistance. This research was funded by the Foundation for Arable Research and the Ministry of Primary Industries.

\section{REFERENCES}

Bekker RM, Bakker JP, Ozinga WA, Thompson K 2003. Seed traits: essential for understanding seed longevity. Annals of Applied Biology 69: 1-9.

Forcella F 2003. Debiting the seedbank: priorities and predictions. Annals of Applied Biology 69: 151-162.

Burnside OC, Wilson RG, Weisberg S, Hubbard KG 1996. Seed longevity of 41 weed species buried 17 years in Eastern and Western Nebraska. Weed Science 44: 74-86.

Dawson JH, Bruns VF 1975. Longevity of barnyardgrass, green foxtail and yellow foxtail seeds in soil. Weed Science 23 (5): 437-440

James TK, Cooper JM 2012. Control of recently introduced weed butterprint (Abutilon theophrasti) in maize. New Zealand Plant Protection 65: 64-68.

James TK, Rahman A, McGill CR, Trivedi P 2011. Biology and survival of broom corn millet (Panicum miliaceum) seed. New Zealand Plant Protection 64: 142-148.

James TK, Rahman A, Trivedi P 2010.Germination of seed from five broadleaf weeds after burial for up to 28 years in two soils. New Zealand Plant Protection 63: 84-89.
James TK, Rahman A, Wardle DA, Bonner KI 1998. Survival of nodding thistle (Carduus nutans) seed buried at different depths in four soils. Proceedings of the New Zealand Plant Protection Conference 51: 33-37.

Long RL, Panetta FD, Steadman KJ, Probert R, Bekker RM, Brooks S, Adkins SW 2008. Seed persistence in the field may be predicted by laboratory-controlled aging. Weed Science 56: 523-528.

Lueschen WE, Andersen RN 1993. Seventeen years of cropping systems and tillage affect velvetleaf (Abutilon theophrasti) seed longevity. Weed Science 41(1): 82-86.

MAF Biosecurity 2010. Bat-wing Passion Flower. Fact sheet MAF Biosecurity New Zealand, Wellington. 1 p.

Masin R, Zuin MC, Otto S, Zanin G 2005. Seed longevity and dormancy of four summer annual grasses weeds in turf. Weed Research 46: 362-370.

Newton R, Hay F, Probert R 2009. Protocol for comparative seed longevity testing. Technical information sheet_01. Seed Conservation Department, Millennium Seed Bank Project, Kew, UK.

Panetta FD, Timmins SM 2004. Evaluating the feasibility of eradication for terrestrial weed incursions. Plant Protection Quarterly 19: 5-11.

Sawma JT, Mohler CL 2002. Evaluating seed viability by an unimbibed seed crush test in comparison with the tetrazolium test. Weed Technology 16: 781-786.

Trivedi PD, James TK, Clearwater MJ 2010. Methods of scarification to overcome dormancy in Bryonia cretica subsp. dioica (Jacq.) Tutin (white bryony) seeds. Poster presented at the NZBIO Conference, Auckland. New Zealand.

Uremis I, Uygur FN 2002. Variation of viability rates of some weed seeds in different depths of the soil by times. Turkiye Herboloji Dergisi 5(1): 23-34. 